Background/introduction A variety of risk-reduction interventions may be suitable for sexual health clinic attendees.

Aim(s)/objectives In the SANTE project, we explored service users' (SU) perceptions of their STI risk, and experiences and preferences for risk reduction interventions.

Methods Semi-structured interviews were conducted with 15 young people (YP) (16-25 years) and 20 MSM ( $\geq 16$ years) from two SH clinics. Data were analysed thematically. Based on these, a Discrete Choice Experiment (DCE) to quantitatively assess YP and MSM preferences for interventions was designed and conducted in three clinics $(\mathrm{n}=371)$.

Results Most participants, despite presenting with symptoms or concerned about STIs, did not perceive themselves to be at risk. Most reported receiving $\mathrm{SH}$ promotion but felt access to accurate information was lacking. While short advert-like videos were acceptable, onscreen material in waiting rooms was deemed inappropriate by some SUs. Opinions on group sessions were mixed. 1:1 sessions were favoured, with talking therapies acceptable if needed. Privacy around mobile apps was a concern while online materials from a reputable source were acceptable. DCE results demonstrated preferences for 'talking interventions', while all interventions were generally preferred to 'nothing'. People strongly disliked peer-led interventions compared to others, and preferred 1:1 to group sessions. Latent class analysis identified three respondent groups, those that preferred talking (56\%), email/text (29\%) or nothing (15\%).

Discussion/conclusion Young people and MSM welcome SH promotion offered through $\mathrm{SH}$ clinics. Triangulation demonstrated strong preferences for 1:1 talking interventions. Awareness of sexual risk was not commensurate with actual risk, suggesting that providers need to direct service users to appropriate interventions.

\section{P110 THE SANTÉ PROJECT: A MIXED-METHODS ASSESSMENT OF OPPORTUNITIES AND CHALLENGES FOR THE DELIVERY OF BRIEF RISK REDUCTION INTERVENTIONS IN SEXUAL HEALTH CLINICS IN ENGLAND - A HEALTHCARE PROVIDER'S PERSPECTIVE}

${ }^{1}$ Carina King*, ${ }^{2}$ Anupama Roy, ${ }^{1}$ Maryam Shahmanesh, ${ }^{1}$ Richard Gilson, ${ }^{2,3}$ Daniel Richardson, ${ }^{1}$ Fiona Burns, ${ }^{1}$ Alison Rodgers, ${ }^{1}$ Nicholas Massie, ${ }^{1} J u l i a$ Bailey, ${ }^{2}$ Carrie Llewellyn. ${ }^{1}$ Department of Infection and Population Health, University College London, London, UK; ${ }^{2}$ Division of Primary Care and Public Health, Brighton and Sussex Medical School, Brighton, East Sussex, UK; ${ }^{3}$ Brighton and Sussex University Trust, Brighton, East Sussex, UK

\subsection{6/sextrans-2016-052718.164}

Background/introduction Sante is a study to improve targeted sexual health promotion in UK sexual health $(\mathrm{SH})$ clinics.

Aim(s)/objectives We explored opportunities and challenges for delivering interventions including 1:1 and group sessions, digital and video interventions.

Methods Semi-structured interviews were conducted by telephone with healthcare providers (HCPs) from a range of clinics, by location, size, and patient mix. Data were analysed thematically using a framework approach. A web-survey was sent to key HCP contacts in SH services in England.

Results Interviews $(n=26)$ showed that digital interventions were viewed as logistically and financially feasible; some clinics reported already using them. All clinics provided brief 1:1 sessions, but challenges to delivery were identified as: lack of evidence for effectiveness on behaviours; costs and staff resourcing; and patient motivation. Videos received mixed opinions, they were seen as a practical option for providing STI information while patients wait, but issues about appropriateness were raised. HCPs had concerns about the feasibility of group sessions within clinic-based settings, while acknowledging their usefulness for outreach. The web-survey is ongoing; preliminary data indicates that clinics would like to be able to offer mobile apps, online education and videos (Table 1).

Discussion/conclusion Staff time, costs and logistics were universal challenges, while group sessions and videos raised issues of privacy in particular. Brief 1:1 interventions are currently widely delivered, and can be tailored to the patient's needs, but are resource-intensive while digital methods despite being uncommon were seen as desirable.

\begin{tabular}{|c|c|c|c|c|c|c|}
\hline & \multicolumn{3}{|c|}{ Level $3(n=36)$} & \multicolumn{3}{|c|}{ Level 2 ( $n=8)$} \\
\hline & \multirow{2}{*}{$\begin{array}{l}\text { Currently } \\
\text { offer }\end{array}$} & \multicolumn{2}{|c|}{ Currently not offered* } & \multirow{2}{*}{$\begin{array}{l}\text { Currently } \\
\text { offer }\end{array}$} & \multicolumn{2}{|c|}{ Currently not offered* } \\
\hline & & $\begin{array}{l}\text { Would } \\
\text { like }\end{array}$ & $\begin{array}{l}\text { Would not } \\
\text { like }\end{array}$ & & $\begin{array}{l}\text { Would } \\
\text { like }\end{array}$ & $\begin{array}{l}\text { Would not } \\
\text { like }\end{array}$ \\
\hline $\begin{array}{l}\text { Educational } \\
\text { videos }\end{array}$ & $0(0 \%)$ & $\begin{array}{l}19 \\
(53 \%)\end{array}$ & $9(25 \%)$ & $0(0 \%)$ & $4(50 \%)$ & $1(13 \%)$ \\
\hline $\begin{array}{l}\text { Online } \\
\text { education }\end{array}$ & $4(11 \%)$ & $\begin{array}{l}20 \\
(63 \%)\end{array}$ & $5(16 \%)$ & $4(50 \%)$ & $\begin{array}{l}4 \\
(100 \%)\end{array}$ & $0(0 \%)$ \\
\hline Mobile 'app' & $1(3 \%)$ & $\begin{array}{l}21 \\
(60 \%)\end{array}$ & $3(9 \%)$ & $0(0 \%)$ & $4(50 \%)$ & $0(0 \%)$ \\
\hline $\begin{array}{l}\text { Single 1:1 } \\
\text { sessions }\end{array}$ & $26(74 \%)$ & $4(40 \%)$ & $2(20 \%)$ & $6(75 \%)$ & $\begin{array}{l}2 \\
(100 \%)\end{array}$ & $0(0 \%)$ \\
\hline $\begin{array}{l}\text { Multiple 1:1 } \\
\text { sessions }\end{array}$ & $17(49 \%)$ & $9(47 \%)$ & $2(11 \%)$ & $3(38 \%)$ & $1(20 \%)$ & $1(20 \%)$ \\
\hline Group sessions & $3(9 \%)$ & $6(18 \%)$ & $18(55 \%)$ & $3(38 \%)$ & & $2(40 \%)$ \\
\hline
\end{tabular}

*Percentages are calculated based on the number of clinics not already providing this service. One clinic reported not providing any interventions.

\section{P111 PERCEPTIONS OF CHLAMYDIA SCREENING, CONTRACEPTION AND HIV TESTING AMONG 16-24 YEAR OLD PATIENTS VISITING A GP SURGERY}

${ }^{1}$ Leah Jones*, ${ }^{1}$ Ellie Ricketts, ${ }^{2}$ Katy Town, ${ }^{1}$ Donna Lecky, ${ }^{1}$ Claire Rugman, ${ }^{2}$ Kate Folkard, ${ }^{2}$ Anthony Nardone, ${ }^{2}$ Thomas Hartney, ${ }^{1}$ Cliodna McNulty. ${ }^{1}$ Primary Care Unit, Public Health England, Gloucester, UK; ${ }^{2}$ National Chlamydia Screening Programme, Public Health England, London, UK

\subsection{6/sextrans-2016-052718.165}

Background A complex intervention based on the Theory of Planned Behaviour significantly increased chlamydia screening in general practice (McNulty et al 2014). It may be more beneficial to extend this intervention to a broader sexual health offer including chlamydia testing, contraception advice and when appropriate, HIV testing (3Cs and HIV).

Aim To determine young adults' opinions of having a broader sexual health offer (3Cs and HIV) at their GP practice.

Methods Thirty interviews were conducted with 9 male and 21 female patients, 16-24 years in English GP practices. Participants were interviewed immediately before or after a routine practice attendance of any type. Data was analysed using a thematic framework and using QSR Nvivo 10.

Results Participants indicated that method of testing, timing and staff member approach were important aspects to chlamydia screening and contraception discussions. Participants displayed a clear preference for the GP practice over other sexual health 
service locations. Items most important to participants were convenience, reassurance, and that the sexual health discussion is appropriate and routine. Barriers identified were embarrassment, unease, lack of time, religion and concern of causing offence. Suggested facilitators include raising awareness, reassuring confidentiality, ensuring the discussion is facilitated by trust and professionalism at the end of the consultation.

Conclusion The majority of participants are happy to be offered $3 \mathrm{Cs}$ and HIV at their GP surgery. Therefore, it is important for GP staff to recognise these preferences and ensure that the full $3 \mathrm{Cs}$ and HIV services are made available and offered to appropriate patients.

\section{P112 X FACTOR MAKEOVER FOR $4^{\text {TH }}$ YEAR MEDICAL STUDENT LECTURES}

${ }^{1} J o h n n y$ Boylan*, ${ }^{2}$ Sophie Forsyth, ${ }^{1,3}$ Patrick Horner. ${ }^{1}$ Bristol Sexual Health Centre, University Hospitals Bristol NHS Foundation Trust, Bristol, UK; ${ }^{2}$ Swindon Sexual Health Clinic, Great Western Hospitals NHS Foundation Trust, Swindon, UK; ${ }^{3}$ School of Social and Community Medicine, University of Bristol, Bristol, UK

\subsection{6/sextrans-2016-052718.166}

Background/introduction Traditionally Year 4 Medical students at Bristol University receive 4 hours of didactic lecture based teaching on sexual health topics. Overall, the feedback is satisfactory but student evaluations consistently denounce the volume of information contained in the lectures.

Aim(s)/objectives To support learner diversity and increase student participation, we decided to revamp the delivery of the sexual health curriculum.

Methods We made the lectures available on the student intranet for background reading and signposted the students towards additional sources of information such as BASHH guidelines. During a study day, 60 students in groups of 5 or 6 were asked to teach their peers using case studies on topics such as vaginal discharge, genital ulcers and sexual assault. Teaching methods included game shows, a rap about syphilis and role-play. There were prizes for the top three presentations (through peer grading) and a prize for the most innovative. A questionnaire, and open discussion were used to obtain feedback on both the old and new teaching formats.

Results Overwhelmingly the students preferred and gained more from the student led case based presentations. They felt more engaged and would recommend it for future groups. Some students felt it was also important to have an opportunity to ask questions about the online lectures in future.

Discussion/conclusion Through this alternative approach to learning new information, we have catered for different learning styles and created a positive learning environment. Peer teaching can be very effective in encouraging critical thinking and producing deeper learning outcomes.

\section{P113 HIV IN SOCIAL MEDIA: WHAT DO YOUTUBE USERS WATCH?}

Suzanne Todd*, Laura Bell, Michael Hunter. Royal Victoria Hospital, Belfast, Ireland

\subsection{6/sextrans-2016-052718.167}

Background/introduction Increased risk-taking behaviour, sexual networks, and sexually transmitted infections have been attributed to the rapid increase in social media use. YouTube is a video sharing, revenue generating website that's content is not scientifically vetted, and any registered user can post media content.

Aim(s)/objectives The objective of this study was to determine how HIV related issues are portrayed on YouTube.

Methods A YouTube account was created using 'worldwide' and 'English UK' settings. The search engine was cleared, Flash Player cache emptied, and cookies removed. Each of the following search terms was used: 'HIV', 'AIDS', 'PrEP' and 'HIV home testing'. Inclusion criteria: first 60 videos. Exclusion criteria: $>10$ minute duration, exclusively non-HIV content, not in English. Each video was scored by 2 investigators.

Results

\begin{tabular}{|c|c|c|c|c|c|c|c|c|c|c|}
\hline \multirow[b]{2}{*}{$\begin{array}{l}\text { Search } \\
\text { Category }\end{array}$} & \multirow{2}{*}{$\begin{array}{l}\text { No. of } \\
\text { YouTube } \\
\text { hits } \\
\text { (n) }\end{array}$} & \multirow{2}{*}{$\begin{array}{l}\text { Views/ } \\
\text { Day } \\
\text { (Median) }\end{array}$} & \multirow{2}{*}{$\begin{array}{l}\text { Engage- } \\
\text { ment/ } \\
\text { view } \\
(\%) \\
\text { (Median) }\end{array}$} & \multicolumn{2}{|c|}{$\begin{array}{l}\text { Any } \\
\text { advert } \\
\text { (n) }\end{array}$} & \multicolumn{3}{|c|}{$\begin{array}{l}\text { Factual } \\
\text { Inaccuracies }(\mathrm{n})\end{array}$} & \multicolumn{2}{|c|}{$\begin{array}{l}\text { Contained } \\
\text { gossip/ } \\
\text { media } \\
\text { (n) }\end{array}$} \\
\hline & & & & Yes & $(\%)$ & Major & Minor & No & Yes & (\%) \\
\hline $\begin{array}{l}\text { AIDS } \\
(\mathrm{n}=30)\end{array}$ & $2,240,000$ & 585 & 0.34 & 16 & (41) & 2 & 5 & 23 & 12 & 40 \\
\hline $\begin{array}{l}\text { Home } \\
\text { Testing } \\
(n=55)\end{array}$ & 212,000 & 3 & 0.17 & 29 & (51) & 1 & 1 & 53 & 0 & 0 \\
\hline $\begin{array}{l}\text { HIV } \\
(\mathrm{n}=39)\end{array}$ & $1,250,000$ & 1153 & 0.8 & 21 & (54) & 3 & 0 & 36 & 16 & 41 \\
\hline $\begin{array}{l}\text { PrEP } \\
(n=29)\end{array}$ & 2,190 & 334 & 0.62 & 16 & (55) & 1 & 3 & 25 & 2 & 7 \\
\hline
\end{tabular}

M: Median Engagement/view: Number of likes, dislikes, and comments/by number of views (\% value)

Discussion/conclusion Social media is an accessible source of information to the general public and healthcare professionals. When four search terms were compared, "HIV" and "AIDS" were most popular. "HIV" generated the most viewer-engagement. Following Charlie Sheen's HIV disclosure and publication of PrEP studies (November 2015), there was a massively increased use of "HIV" and "PrEP" search terms. 10\% (15/149) of videos contained factual inaccuracies with $40 \%(6 / 15)$ potentially causing significant harm. Due to high rate of embedded advertisements, inaccurate material, and material which could stigmatise PLWHA, it is vital that Public Health/HIV clinicians harness the potential of social media, are aware of the associated risks and strive to promote accurate information to patients.

\section{P114 CONCORDANCE OF CHLAMYDIA INFECTIONS OF THE RECTUM AND URETHRA IN SAME-SEX MALE PARTNERSHIPS: A CROSS-SECTIONAL ANALYSIS}

${ }^{1}$ Hannah McCall ${ }^{*},{ }^{1,2}$ Nataliya Brima, ${ }^{1}$ Patrick French. ${ }^{1}$ Mortimer Market Centre, Central \& North West London NHS Foundation Trust, London, UK; ${ }^{2}$ Research Department of Infection and Population Health, University College London, London, UK

\subsection{6/sextrans-2016-052718.168}

Background Sexual health services should ask all high risk attenders about drug and alcohol use. However, the impact of drug and alcohol use on STI epidemiology remains uncertain.

Aims To audit drug and alcohol history taking after introduction of a screening tool and to describe the patterns of use and associations with STI diagnoses. 